\title{
Educação do Campo em giro decolonial: a experiência do Tempo Comunidade na Universidade Federal Fluminense (UFF) ${ }^{1}$
}

\author{
Francisca Marli Rodrigues de Andrade ${ }^{1}$, Letícia Pereira Mendes Nogueira ${ }^{2}$, Lucas do Couto Neves ${ }^{3}$, Marcela Pereira Mendes \\ Rodrigues $^{4}$ \\ 1, 2, 3, 4 Universidade Federal Fluminense - UFF. Departamento de Ciências Humanas (PCH). Avenida João Jasbick, s/nº, Bairro \\ Aeroporto. Santo Antônio de Pádua - RJ. Brasil. \\ Autor para correspondência/Author for correspondence: marli_andrade@id.uff.br
}

RESUMO. A Educação do Campo no Brasil, em cinco décadas, vem construindo uma prática educativa que valoriza e inclui os sujeitos, os saberes e as experiências sociais do campo; ou seja, a Pedagogia da Alternância. Em âmbito universitário, a Alternância reorganiza os espaços/tempos de aprendizagens em Tempo Universidade e Tempo Comunidade e, portanto, propõe questionamentos à lógica da colonialidade/modernidade do saber, imposta à América Latina. Nessa reorganização, a presente pesquisa tem por objetivo: conhecer o processo de construção do Tempo Comunidade, implementado na Licenciatura Interdisciplinar em Educação do Campo (UFF) para, então, identificar os elementos pedagógicos decoloniais que potencializam a formação de educadores do campo. Metodologicamente, adotamos uma proposta de pesquisa qualitativa inscrita no enfoque interpretativo. Para coletar as informações realizamos entrevistas semiestruturadas com 5 docentes e 12 estudantes do curso; análise documental dos 12 projetos dos eixos temáticos do Tempo Comunidade. Os principais resultados sinalizam a importância do Tempo Comunidade na formação de educadores do campo, bem como nos processos de transformação da realidade. Igualmente, o poder da ação-reflexão do Tempo Comunidade em desencadear ações de fortalecimento da cidadania e da organização de lutas emancipatórias.

Palavras-chave: Educação do Campo, Pedagogia da Alternância, Formação de Educadores do Campo, Tempo Comunidade, Decolonialidade.

\begin{tabular}{|l|l|l|l|l|l|l|} 
RBEC & Tocantinópolis/Brasil & v. 4 & e7178 & $10.20873 /$ uft.rbec.e7178 & 2019 & ISSN: 2525-4863 \\
\hline
\end{tabular}




\title{
Rural Education in a Decolonial Turn: the Community- Time Experience at the Fluminense Federal University (UFF)
}

\begin{abstract}
Rural Education in Brazil, in five decades, has been constructing an educational practice that values and includes the subjects, the lores and the social experiences of the countryside; that is, the Pedagogy of Alternation. In the university context, Alternance reorganizes the spaces of learning in Community-Time (CT) and School-Time (ST) and, therefore, proposes questions to the logics of colonization/modernity of knowledge, imposed on Latin America. In this reorganization, the present research has as objective: to know the process of construction of Community-Time, implemented in the Interdisciplinary Degree in Rural Education (UFF), to identify decolonial pedagogical elements that potentiate the formation of educators in the rural zone. Methodologically, we adopted a qualitative-oriented research, which is inscribed in the interpretative approach. To collect data, we performed semistructured interviews with 5 teachers and 12 students; documentary analysis of the 12 projects of the Thematic Fields of Community-Time. The main results point to the importance of Community-Time in of rural educators' formation as well as in the processes of transformation of reality. Likewise, the power of action-reflection of the Community-Time in encouraging actions to strengthen citizenship and the organization of emancipatory struggles.
\end{abstract}

Keywords: Rural Education, Pedagogy of Alternation, Training of Rural Educators, Community-Time, Decolonization. 


\section{Educación del Campo en giro decolonial: la experiencia del Tiempo Comunidad en la Universidad Federal Fluminense (UFF)}

RESUMEN. La Educación del Campo en Brasil, en cinco décadas, ha estado construyendo una práctica educativa que valora e incluye los sujetos, el conocimiento y las experiencias sociales del campo; es decir, la Pedagogía de la Alternancia. En el contexto universitario, la Alternancia reorganiza los espacios/tiempos de aprendizaje en Tiempo Universidad y Tiempo Comunidad y, por lo tanto, propone cuestionamientos a la lógica de la colonialidad/modernidad del saber impuesta a la América Latina. En esta reorganización, la presente investigación tiene como objetivo: conocer el proceso de construcción del Tiempo Comunitario, implementado en la Licenciatura Interdisciplinar en Educación del Campo (UFF) para, entonces, identificar los elementos pedagógicos decoloniales que potencializan la formación de educadores del campo. Metodológicamente, adoptamos una propuesta de investigación cualitativa inscrita en el enfoque interpretativo. Para recopilar la información realizamos entrevistas semiestructurada con 5 profesores y 12 estudiantes del curso; análisis documental de los 12 proyectos de los ejes temáticos del Tiempo Comunidad. Los principales resultados indican la importancia del Tiempo Comunidad en la formación de los educadores del campo, así como en los procesos de transformación de la realidad. Igualmente, el poder de la acciónreflexión del Tiempo Comunidad en la activación de acciones para fortalecer la ciudadanía y la organización de luchas emancipatorias.

Palabras clave: Educación del Campo, Pedagogía de la Alternancia, Formación de Educadores del Campo, Tiempo Comunidad, Decolonialidad. 


\section{Introdução}

Os movimentos sociais do campo, em sua luta pela terra, vêm reivindicando o direito a uma educação que contemple as suas demandas sócio-históricas. Tais movimentos entendem que a Educação do Campo se constitui como um importante instrumento de compreensão das relações políticas, econômicas, sociais e ambientais que atravessam o território camponês. Logo, a educação pleiteada pelos movimentos populares "não se aplica às classes que detêm o poder econômicopolítico". (Ribeiro, 2010, p. 47). Ao contrário, auxilia os atores sociais na organização da consciência de classe à qual pertencem e, portanto, suas demandas por uma educação diferenciada. Nessa diferenciação, a construção da Educação do Campo se dá em um espaço de lutas e embates políticos dos movimentos sociais, em defesa de uma educação que disponha de um plano político-pedagógico que possa atender as especificidades dos sujeitos do campo. Entre essas especificidades encontra-se a Pedagogia da Alternância, a qual pode ser compreendida, também, como elemento de desarticulação das práticas educativas coloniais, promotoras de desenraizamento de identidades e de territórios.

A Pedagogia da Alternância na formação de educadores do campo pode ser considerada como uma prática decolonial por muitos aspectos, sobretudo, porque "permite aos jovens do campo a possibilidade de continuar os estudos e de ter acesso aos conhecimentos científicos e tecnológicos não como algo dado por outrem, mas como conhecimentos conquistados e construídos a partir da problematização de sua realidade". (Cordeiro, Reis \& Hage, 2011, p. 116). Essa problematização potencializa diálogos e práticas sociais em diferentes espaçostempos de aprendizagem, de construção e de transformação da realidade; ou seja, Tempo Universidade e Tempo Comunidade. Evoca, portanto, a dimensão da indissociabilidade "entre os conhecimentos sistematizados no ambiente universitário e os conhecimentos historicamente construídos pelos camponeses, nos seus processos de trabalho e de organização das condições de reprodução da vida no campo e nos processos organizativos de classe". (Santos, 2012, p. 632). Logo, tanto as condições de reprodução da vida, quanto os processos organizativos de classe, revelam-se como ferramentas potentes para desestabilizar as violências perpetradas pela lógica da colonialidade/modernidade aos povos do campo. Propõe, assim, 
processos educativos em giro decolonial; isto é, as tentativas de marcar:

(a) A narrativa original que resgata $\mathrm{e}$ insere a América Latina como o continente fundacional do colonialismo, e, portanto, da modernidade; (b) a importância da América Latina como primeiro laboratório de teste para o racismo a serviço do colonialismo; (c) $\mathrm{o}$ reconhecimento da diferença colonial, uma diferença mais difícil de identificação empírica na atualidade, mas que fundamenta algumas origens de outras diferenças; (d) a verificação da estrutura opressora do tripé colonialidade do poder, saber e ser como forma de denunciar e atualizar a continuidade da colonização e do imperialismo, mesmo findados os marcos históricos de ambos os processos; (e) a perspectiva decolonial, que fornece novos horizontes utópicos e radicais para o pensamento da libertação humana, em diálogo com a produção de conhecimento. (Ballestrin, 2013, p. 110).

O giro decolonial está sendo construído por diferentes acadêmicos, ambientalistas, sindicalistas, líderes de movimentos sociais e outros protagonistas, os quais, desde o século $\mathrm{XX}$, vêm provocando renovações e tensões analíticas e utópicas, principalmente, nas Ciências Sociais Latino-Americanas. Nesse embate, as epistemologias ameríndias, em mais de 500 anos, têm construído diferentes formas de luta decolonial contra os processos de invasão, apropriação e violência (Andrade, 2018; 2019). Em tal luta, o território -enquanto expressão de todas as formas de vida, de cultura, de ancestralidade e de identidade - revela-se extremamente importante (Andrade, 2019). Sobre as contribuições ameríndias às lutas decoloniais, Walter Mignolo (2007, p. 27), em seus estudos de mais de duas décadas, desenvolveu a seguinte tese: "el pensamiento decolonial emergió en la fundación misma de la modernidad/colonialidad como su contrapartida. Y eso ocurrió en las Américas, en el pensamiento indígena y en el pensamiento afro-cari-beño" ${ }^{\text {[2] }}$. Essa tese nos remete aos povos, comunidades e nacionalidades que foram/são ultrajadas, entre outras violências, pela lógica da colonização; isto é, as comunidades tradicionais e camponesas.

$\mathrm{Na}$ construção do giro decolonial na América Latina, "el surgimiento del concepto 'colonialidad del ser' responde, pues, a la necesidad de aclarar la pregunta sobre los efectos de la colonialidad en la experiencia vivida, y no sólo en la mente de sujetos subalternos". (MaldonadoTorres, 2007, p. 130). Entre tais efeitos, situamos o racismo epistêmico que, intrínseco ao universalismo abstrato ocidental, descaracteriza e deslegitima os povos tradicionais, seus discursos, seus espaços de fala e suas identidades (Grosfoguel, 2007). Nesse sentido, a proposta política e epistemológica da 
Educação do Campo revela-se como uma possibilidade para confrontar tal deslegitimação. Pois, um dos significados da Educação do Campo consiste em "reverter as visões e os tratos históricos brutais de produção desses coletivos como inferiores, à margem da história intelectual, cultural, social e pedagógica". (Arroyo, 2012, p. 363). Na luta por esse projeto, os embates dos movimentos sociais, em defesa de uma educação que promova o acesso e a permanência dos camponeses no território, não estão desvinculados dos elementos que desestabilizam a colonialidade do poder/saber/ser. Isto porque:

A Educação do Campo nasceu como mobilização/pressão dos movimentos sociais por uma política educacional para comunidades camponesas: nasceu da combinação das lutas sem-terras pela implementação de escolas públicas nas áreas de reforma agrária com as lutas de resistência de inúmeras organizações e comunidades camponesas para não perder suas escolas, suas experiências de educação, suas comunidades, seu território, sua identidade. (Caldart, 2008, p. 71).

No processo de construção ideológica da Educação do Campo, sobretudo quando estamos a comemorar uma década de expansão dos cursos de Formação Universitária de Educadores do Campo, destacamos a luta camponesa contra o projeto hegemônico colonizador escolar. Em tal projeto, algumas sutilezas são incorporadas com o propósito de demarcar posições ideológicas que convergem em sentido à subalternização dos povos do campo e, assim, à negação do acesso e da permeância no território. Nesse contexto, a Educação do Campo, enquanto elemento político e pedagógico decolonial, não está desvinculada das disputas conceituais que traduzem os sentidos opostos da colonização. A superação do conceito de Educação Rural, defendido na Lei de Diretrizes e Bases da Educação (LDB), Lei $n^{\circ}$ 9.394/96 (Brasil, 1996), revela os avanças e as conquistas das lutas sociais emancipatórias. Esses avanços se apresentam, sobretudo, quando os movimentos sociais do campo entendem que, de acordo com Caldart (2002, p. 18), a Educação no Campo significa que "o povo tem direito a ser educado no lugar onde vive". Por sua vez, a Educação do Campo, ressalta que "o povo tem direito a uma educação pensada desde o seu lugar e com a sua participação, vinculada à sua cultura e às suas necessidades humanas e sociais". (Caldart, 2002, p. 18).

Apesar das posições ideológicas contraditórias, a abertura proposta à discussão de conteúdos curriculares e metodologias apropriadas à educação rural diferenciada, sinalizada na LDB de 1996, ganha força em âmbito nacional. Nesse cenário, no ano de 1997, houve a 
realização do I Encontro Nacional de Educadores e Educadoras da Reforma Agrária (I ENERA), considerado como marco inicial do Movimento Nacional de Educação do Campo (Molina, 2015). Nessa linha cronológica, a luta camponesa comemorou, no ano de 2010, a Política Nacional de Educação do Campo, implementada pelo Decreto $\mathrm{n}^{0} 7352$, de 04 de novembro de 2010. Tal decreto enfatiza que, conforme o artigo $4^{\mathrm{o}}$, a Política de Educação do Campo não se destina somente à educação básica, mas também abrange o ensino superior para os povos do campo (Brasil, 2010). Enquanto desdobramento do Decreto $\mathrm{n}^{\mathrm{o}} 7352$, no ano de 2012 foi constituído o Programa de Apoio à Formação Superior em Licenciatura em Educação do Campo (Procampo), cujo objetivo principal consiste em apoiar a inserção de cursos de Licenciatura em Educação do Campo nas universidades públicas de todo o país.

Com a aprovação do Procampo, ampliou-se o debate em torno das questões educacionais destinadas ao território camponês, uma vez que a formação inicial de educadores do campo está atrelada à construção de uma política educacional que atenda aos anseios e às demandas das populações do campo; em especial, a emancipação e o resgate dos elementos identitários (Santos, 2012). Nesse sentido, um dos aspectos considerados no Procampo refere-se à organização teóricometodológica curricular do curso; ou seja, a refundação da Educação do Campo a partir de lógicas de emancipação contrahegemônicas. Em outras palavras, um projeto educativo potente, capaz de desestabilizar os processos de dominação impostos pelo pensamento colonial, cujo objetivo consiste em desenraizar os sujeitos do campo de suas identidades e dos seus territórios, em detrimento do avanço do capital (Andrade, Nogueira \& Rodrigues, 2019). Esse projeto se concretiza em articulação com outros componentes políticos e princípios teóricometodológicos da Educação do Campo, voltados à emancipação dos seus atores sociais. Entre tais princípios encontra-se a Pedagogia da Alternância, a qual prevê dois espaços/tempos distintos de aprendizagem; isto é, Tempo Escola e Tempo Comunidade.

Por Tempo Escola (TE), entende-se uma etapa do curso correspondente a um semestre acadêmico, num período aproximado de 50 dias letivos, com oito horas diárias de aula. Já o Tempo Comunidade (TC) destina-se ao período em que os estudantes estão em suas comunidades de origem, quando são realizados estudos e pesquisas que levam a uma reflexão teórico-prática das questões pertinentes à Educação do Campo, aos processos de ensino, de aprendizagem, à gestão escolar e da comunidade e à realidade concreta onde a escola está inserida. Essas 
atividades são orientadas pelos professores-formadores do curso ainda no TE, e acompanhadas pelos mesmos. (Ferreira \& Molina, 2016, p. 1710).

Com esses elementos, destacamos que "o Tempo Comunidade potencializa o processo de formação dos educadores do campo, uma vez que por meio do diálogo entre a teoria e a prática é possível aprender com os valores e com os conhecimentos tradicionais para se pensar novas formas de ensino-aprendizagem". (Andrade et al. 2019, p. 162). Nesse diálogo, Ribeiro (2010) elucida que a expressão Pedagogia da Alternância tem vários significados, os quais irão variar de acordo com algumas condições, tais como: os sujeitos que a apropriam; as regiões onde são realizadas; e as condições do local, que podem favorecer ou dificultar a prática da Alternância. Embora a Alternância possua diferentes concepções teóricas, todas apresentam um elemento em comum; isto é, "o trabalho como princípio educativo de uma formação humana integral, que articula dialeticamente o trabalho produtivo ao ensino formal". (Ribeiro, 2010, p. 293). Nessa articulação, a autonomia, a autodeterminação e a liberdade revelam-se como preponderantes na formação de educadores do campo, permitindo-lhes desestabilizar as lógicas coloniais opressoras que, secularmente, têm imposto uma condição de subalternidade epistemológica aos povos do campo.

\section{Pesquisar com a Educação do Campo: a construção da experiência social da UFF em giro decolonial}

A implementação da Licenciatura Interdisciplinar em Educação do Campo da Universidade Federal Fluminense (UFF) foi concretizada em 2015. O projeto do curso configura como resultado do Programa Nacional de Educação do Campo (Pronacampo), lançado em 2012. Tal programa tinha previsto, entre os objetivos principais, subsidiar os estados, o Distrito Federal e os municípios oferecendo-lhes apoio técnico e financeiro “para implementação da Política Nacional de Educação do Campo, devendo atender Escolas do Campo e Quilombolas, a partir de quatro eixos de ação: 1. Gestão e Práticas Pedagógicas; 2. Formação de Educadores; 3. Educação Profissional e Tecnológica; e 4. Infraestrutura" (Molina, 2015, p. 147). Nesse sentido, destacamos que o Eixo 2 preocupou-se, especificamente, com a "ação do Estado responsável por apoiar e fazer acontecer a implantação dos 42 novos cursos de Licenciatura em Educação do Campo LEDOC, através de um Subprograma intitulado 'Programa de Apoio às 
Licenciaturas em Educação do Campo Procampo"”. (Molina, 2015, p. 147).

É nesse contexto que se concretiza a conquista dos movimentos sociais da Educação do Campo, em âmbito de reivindicações históricas pela formação de educadores do campo para atender direitos educativos diferenciados. É nesse espaço/tempo de ganhos políticos que, em matéria de diversidade racial e epistemológica, o Estado brasileiro passa a integrar diferentes protagonistas sociais e culturas à universidade. Essa integração fortalece as lutas contra-hegemônicas, para então questionar, entre outros elementos: o mito da democracia racial; as práticas educativas coloniais; os processos de desenraizamento das populações do campo de suas identidades e dos seus territórios; as injustiças ambientais e as violações dos direitos das populações do campo e da natureza. Todos esses elementos integram o projeto do curso de formação de Educadores do Campo da Universidade Federal Fluminense (UFF) e, ao tempo, articulam possibilidades de desestabilização da modernidade/colonialidade imposta à América Latina. Isto porque o referido curso, em nosso entendimento, apresenta aspectos potentes para "construir puentes de convergencia entre proyectos intelectuales, entre comunidades interpretativas y entre las disciplinas que estudian lo social-cultural, y también entre éstas y los saberes locales". (Walsh, 2013, p. 14). Entre tais pontes, sinalizaremos as propostas dos 12 eixos temáticos desenvolvidos no Tempo Comunidade.

Quadro 1 - Eixos Temáticos do Tempo Comunidade - Licenciatura Interdisciplinar em Educação do Campo da UFF.

\begin{tabular}{|c|l|}
\hline Eixos & \multicolumn{1}{|c|}{ Objetivos } \\
\hline $\begin{array}{c}\text { Bioética como ferramenta } \\
\text { filosófico-pedagógica }\end{array}$ & $\begin{array}{l}\text { - Pensar a Educação do Campo a partir do recorte da bioética, } \\
\text { identificando e problematizando marcadores da exclusão para, enfim, } \\
\text { interseccioná-los. } \\
\text { - Incentivar a reflexão sobre preconceitos, discriminações, violências e } \\
\text { opressões bioéticas que atravessam as relações estabelecidas no interior, } \\
\text { nas escolas do campo e nos movimentos sociais rurais, com o intuito de } \\
\text { identificarmos vozes que permanecem subalternizadas e corpos } \\
\text { invisibilizados que buscam resistir nos caminhos impostos pelas regras } \\
\text { vigentes. }\end{array}$ \\
\hline $\begin{array}{c}\text { Cidadania no campo: } \\
\text { associativismo, sindicatos } \\
\text { rurais e organização no campo } \\
\text { na região de Santo Antônio de } \\
\text { Pádua }\end{array}$ & $\begin{array}{l}\text { - Mapear associações, ainda existentes ou não, realizar o levantamento } \\
\text { associações rurais. } \\
\text { - Compreender as redes de apoio, a luta por direitos, a questão agrária na } \\
\text { região e o processo de construção da cidadania desses sujeitos históricos. }\end{array}$ \\
\hline $\begin{array}{c}\text { Cotidianos, memórias, } \\
\text { narrativas e história oral }\end{array}$ & $\begin{array}{l}\text { Pesquisar, a partir dos cotidianos vividos, as memórias de sujeitos } \\
\text { individuais e coletivos, nas suas lutas por melhores condições de }\end{array}$ \\
\hline
\end{tabular}




\begin{tabular}{|c|c|}
\hline & $\begin{array}{l}\text { existência, com o uso da história oral e de imagens, preconizando a } \\
\text { valorização das pessoas nas suas múltiplas redes educativas, na sua } \\
\text { inserção num amplo leque de saberes/fazeres ligados à natureza, ao meio } \\
\text { ambiente, à agroecologia, à educação, às diferentes culturas, às novas } \\
\text { formas de pensar a relação cidade/campo, dentre outros. }\end{array}$ \\
\hline $\begin{array}{c}\text { Educação e Justiça Ambiental } \\
\text { no Vale do Rio Pomba }\end{array}$ & $\begin{array}{l}\text { - Investigar situações de conflitos, cenários de injustiça ambiental e } \\
\text { movimentos de resistência atuantes no campo, vinculados à população } \\
\text { camponesa, de forma especial, na região compreendida pelos municípios } \\
\text { que compõe o Vale do Rio Pomba. } \\
\text { - Promover a discussão do papel da educação junto às populações } \\
\text { camponesas enquanto ferramenta de resistência e empoderamento para o } \\
\text { enfrentamento de situações de injustiça ambiental. }\end{array}$ \\
\hline $\begin{array}{l}\text { Educação e Sustentabilidade: } \\
\text { práticas pedagógicas e } \\
\text { comunitárias }\end{array}$ & $\begin{array}{l}\text { - Discutir e significar o conceito e as práticas educativas em } \\
\text { sustentabilidade, dentro e fora das escolas. } \\
\text { - Realizar práticas pedagógicas e comunitárias que dialogam com as } \\
\text { concepções de sustentabilidade associadas às experiências sociais } \\
\text { construídas em diferentes contextos históricos e geográficos, sobretudo } \\
\text { em âmbito do campesinato, aproximando os conhecimentos acadêmicos } \\
\text { das práticas e saberes do campo. }\end{array}$ \\
\hline $\begin{array}{l}\text { Educação popular em saúde: } \\
\text { ênfase nas crianças e mulheres }\end{array}$ & $\begin{array}{l}\text { - Reconhecer a importância do saber e da experiência compartilhados em } \\
\text { matéria de saúde, voltados à participação, controle social e gestão } \\
\text { participativa; formação, comunicação e produção de conhecimento; } \\
\text { cuidado em saúde; intersetorialidade e diálogos multiculturais. } \\
\text { Direcionando-os para o cuidado em saúde, prioritariamente para crianças } \\
\text { e mulheres do campo, das florestas e das águas. }\end{array}$ \\
\hline $\begin{array}{l}\text { Mapeando as Escolas do } \\
\text { Campo no Rio de Janeiro }\end{array}$ & $\begin{array}{l}\text { - Debruçar-se sobre um mapeamento das escolas do campo em todas as } \\
\text { regiões do Rio de Janeiro para construir uma pequena amostragem sobre } \\
\text { a região que possui ainda o maior número de Escolas do Campo. }\end{array}$ \\
\hline $\begin{array}{l}\text { Negrxs na Universidade: } \\
\text { negritude, educação e } \\
\text { movimentos sociais }\end{array}$ & $\begin{array}{l}\text { - Propiciar aos estudantes a oportunidade de trabalhar com temas } \\
\text { relacionados à educação em seu mais amplo espectro. Pensando sempre } \\
\text { nas relações entre negritude e educação, a partir dos temas como: acesso } \\
\text { à universidade; construção do movimento negro universitário; técnicas } \\
\text { de Ensino e aplicação da Lei }{ }^{\circ}{ }^{\circ} 10639 / 03 \text { nas escolas, enfatizando } \\
\text { Educação Indígena e Quilombola; pesquisas sobre a História do Negro } \\
\text { no Brasil. }\end{array}$ \\
\hline $\begin{array}{l}\text { Programa de Estágio em } \\
\text { vivência rural: práticas } \\
\text { interdisciplinares em } \\
\text { Educação do Campo }\end{array}$ & $\begin{array}{l}\text { - Desenvolver ações na área de análise de processos socioterritoriais } \\
\text { agrários, rurais e agrícolas, tendo por foco os fenômenos que abrangem o } \\
\text { desenvolvimento de territórios rurais sustentáveis a partir de referenciais } \\
\text { da Ciência Geográfica, Agroecologia e ciências afins. }\end{array}$ \\
\hline $\begin{array}{l}\text { Saúde e adoecimento das } \\
\text { populações remanescentes: } \\
\text { produção de material voltado } \\
\text { ao cuidado da anemia } \\
\text { falciforme }\end{array}$ & $\begin{array}{l}\text { - Criar uma proposta de intervenção junto à população remanescente no } \\
\text { intuito de minorar os danos causados pela anemia falciforme nas regiões } \\
\text { de Queimados e Cruzeirinho de Cima, locais onde foram identificadas a } \\
\text { anemia falciforme. }\end{array}$ \\
\hline $\begin{array}{l}\text { Territórios de moradia e } \\
\text { trabalho: organização } \\
\text { comunitária das famílias } \\
\text { trabalhadoras }\end{array}$ & $\begin{array}{l}\text { - Articular e desenvolver pesquisas relativas ao campo de demandas por } \\
\text { espaços de reprodução sociocultural, resistências e saberes de famílias } \\
\text { trabalhadoras em territórios no campo e na cidade que, envolvem ações e } \\
\text { políticas de mobilização e organização comunitária, por meio das quais } \\
\text { se estabelecem específicas relações de dependência e autonomia entre } \\
\text { estes coletivos, associações, movimentos sociais, agências } \\
\text { governamentais e não governamentais. }\end{array}$ \\
\hline
\end{tabular}


Andrade, F. M. R., Nogueira, L. P. M., Neves, L. C., \& Rodrigues, M. P. M. (2019). Educação do Campo em giro decolonial: a experiência do Tempo Comunidade na Universidade Federal Fluminense (UFF)...

\begin{tabular}{|l|l|}
\hline $\begin{array}{c}\text { Trincheiras Espaciais } \\
\text { Simbólicas: espaço, cultura, } \\
\text { identidade e memória social }\end{array}$ & $\begin{array}{l}\text { - Desenvolver pesquisas, intervenções, vivências na cidade de Pádua ou } \\
\text { outras, com objetivo de registrar, resgatar e/ou desvelar o espaço vivido, } \\
\text { a cultura popular e as memórias sociais construídas no cotidiano das } \\
\text { cidades, considerando os resíduos históricos do processo de ocupação do } \\
\text { solo e os elementos que possam influenciar na valorização simbólica e } \\
\text { econômica dos lugares na cidade. }\end{array}$ \\
\hline
\end{tabular}

Fonte: Elaboração nossa - Dados disponibilizados pela Secretaria do Curso (junho de 2019).

Diante dos cenários atuais de corrosão da democracia, a Licenciatura Interdisciplinar em Educação do Campo da Universidade Federal Fluminense, campus de Santo Antônio de Pádua, em seus eixos temáticos de Tempo Comunidade, reúne elementos decoloniais que visam promover lutas sociais, políticas, ontológicas e epistêmicas de libertação. Tal curso tem como finalidade a formação de educadores do campo que, com ênfase na área do conhecimento de Ciências Humanas e Sociais, está construindo um sistema de Alternância de acordo com as especificidades do corpo discente. No Tempo Universidade (TU), os estudantes podem vivenciar um currículo interdisciplinar, com discussões e construções epistêmicas que contemplam a pluralidade da realidade do território camponês brasileiro. Por sua vez, durante o Tempo Comunidade (TC) os estudantes potencializam práticas políticopedagógicas, as quais lhes permitem compreender: a realidade das escolas e das populações do campo; o ecocídio e demais processos de apropriação e comercialização voraz da natureza; o genocídio na luta pela terra e o etnocídio dos povos originários e tradicionais, de seus saberes, conhecimentos ancestrais e alteridades; entre outras. A partir dessa compreensão,

contribuir, significativamente, na construção e no fortalecimento das lutas emancipatórias e das práticas educativas decoloniais.

Atualmente o curso é formado por treze docentes, vagas oriundas do Procampo, com formações em programas de doutoramento em diferentes áreas de ensino: Antropologia (2); Educação (2); Filosofia (3); Geografia (1); História das Ciências e da Saúde (3); Psicologia Social (1); Saúde Coletiva (1). Outros docentes do Departamento de Ciências Humanas (PCH), também colaboram com o curso e oferecem disciplinas, na maioria das vezes optativas. Por sua vez, o corpo discente é formado por um total de 90 estudantes matriculados e ativos; ou seja, aqueles que estão regularmente matriculados, em situação de inscritos em disciplinas e em trancamento, mas que podem destrancar e retornar aos estudos ${ }^{[3]}$. Dessa comunidade universitária participaram desta pesquisa cinco docentes e doze estudantes, cujas 

decolonial: a experiência do Tempo Comunidade na Universidade Federal Fluminense (UFF)...

características acadêmicas serão mostradas

a seguir. A pesquisa foi orientada pelo

objetivo principal de: conhecer o processo

de construção do Tempo Comunidade,

implementado na Licenciatura
Interdisciplinar em Educação do Campo (UFF) para, então, identificar os elementos pedagógicos decoloniais que potencializam a formação de educadores do campo.

Quadro 2 - Características acadêmicas dos sujeitos da pesquisa e vinculação ao Tempo Comunidade.

\begin{tabular}{|c|c|c|c|}
\hline \multirow{2}{*}{ Eixos Temáticos do Tempo Comunidade } & \multicolumn{2}{|c|}{$\begin{array}{c}\text { Docentes } \\
\text { Coordenação de Eixos }\end{array}$} & \multirow{2}{*}{$\begin{array}{c}\text { Estudantes } \\
\begin{array}{c}\text { Períodos que estão } \\
\text { cursando }\end{array}\end{array}$} \\
\hline & $\begin{array}{l}\text { Áreas de } \\
\text { formação }\end{array}$ & $\begin{array}{l}\text { Ingresso no } \\
\text { curso }\end{array}$ & \\
\hline Bioética como ferramenta filosófico-pedagógica & $\begin{array}{l}\text { Filosofia } \\
\left(\mathrm{P} 2^{*}\right)\end{array}$ & Março/ 2016 & $3^{\circ}$ Período $\left(E 7^{* *} ; \mathrm{E} 8\right)$ \\
\hline $\begin{array}{l}\text { Cidadania no campo: associativismo, sindicatos } \\
\text { rurais e organização no campo na região de } \\
\text { Santo Antônio de Pádua }\end{array}$ & --- & --- & $5^{\circ}$ Período (E12) \\
\hline Cotidianos, memórias, narrativas e história oral & --- & --- & $8^{\circ}$ Período (E3) \\
\hline $\begin{array}{l}\text { Educação e Sustentabilidade: } \\
\text { pedagógicas e comunitáricas }\end{array}$ & --- & --- & $\begin{array}{l}5^{\mathrm{o}} \text { Período (E10) } \\
8^{\mathrm{o}} \text { Período }(\mathrm{E} 1 ; \mathrm{E} 9)\end{array}$ \\
\hline $\begin{array}{l}\text { Mapeando as Escolas do Campo no Rio de } \\
\text { Janeiro }\end{array}$ & $\begin{array}{l}\text { Antropologia } \\
\text { (P1) }\end{array}$ & $\begin{array}{l}\text { Julho/ } \\
2014^{\#}\end{array}$ & $1^{\circ}$ Período (E11) \\
\hline $\begin{array}{l}\text { Negrxs na Universidade: negritude, educação e } \\
\text { movimentos sociais }\end{array}$ & $\begin{array}{l}\text { História } \\
\text { (P3) }\end{array}$ & $\begin{array}{c}\text { Dezembro/ } \\
2013^{\#}\end{array}$ & $3^{\circ}$ Período (E4; E5) \\
\hline $\begin{array}{l}\text { Programa de Estágio em vivência rural: práticas } \\
\text { interdisciplinares em Educação do Campo }\end{array}$ & $\begin{array}{l}\text { Geografia } \\
\text { (P5) }\end{array}$ & $\begin{array}{c}\text { Fevereiro/ } \\
2016\end{array}$ & $8^{\circ}$ Período (E3) \\
\hline $\begin{array}{l}\text { Saúde e adoecimento das populações } \\
\text { remanescentes: produção de material voltado ao } \\
\text { cuidado da anemia falciforme }\end{array}$ & $\begin{array}{l}\text { História } \\
\text { (P4) }\end{array}$ & $\begin{array}{l}\text { Agosto/ } \\
2015\end{array}$ & $3^{\circ}$ Período (E6) \\
\hline
\end{tabular}

Fonte: Elaboração nossa - Dados da pesquisa (junho de 2019).

*Código atribuído para identificação das entrevistas de docentes.

**Código atribuído para identificação das entrevistas de estudantes.

\#Docentes que trabalharam no processo de implementação do curso, o que ocorreu em março de 2015.

A colaboração dos cinco docentes e dos doze estudantes com a pesquisa aconteceu por meio da realização de entrevistas semiestruturadas, nas quais os dados foram coletados em junho de 2019. Todas as entrevistas foram realizadas de forma aleatória, de acordo com as respostas positivas aos convites feitos a oito docentes -com maior antiguidade de atuação no curso- e quatorze estudantes.
Ademais das entrevistas, realizamos análise documental de todos os doze projetos dos eixos temáticos do Tempo Comunidade, concentrando-nos nos objetivos dos mesmos, tal como apresentado no quadro 1. Para tratamento e análise dos dados, utilizamos o software de domínio público $\boldsymbol{R}$ e, em seguida, elaboramos um gráfico de nuvens de palavras. Com os resultados apontados no 
gráfico e com o marco teórico da pesquisa, estabelecemos as seguintes categorias de análise: a) importância atribuída ao Tempo Comunidade; b) aprendizagens que docentes e estudantes consideram mais significativas; c) conhecimentos que foram potencializados na formação.

As abordagens teóricas adotadas na pesquisa se inscrevem nas seguintes colonialidades: do poder, a qual determina os processos econômicos e políticos; do saber, uma vez que esta estabelece as violências epistêmicas, linguísticas e culturais; do ser, a qual assegura a opressão e controle dos desejos, da sexualidade e das funções sociais atribuídas aos gêneros (Mignolo, 2007). Todas essas categorias analíticas determinam a vida das populações do campo, por isso destacamos, nesta pesquisa, a colonialidade do saber, pensada enquanto práticas educativas coloniais e, portanto, opressoras das diversidades -culturais, raciais e de gênero, promotora de violências epistêmicas, desenraizadoras dos sujeitos do campo das suas identidades e dos seus territórios. Pensar a desestabilização dessa colonialidade, principalmente nos processos de formação de educadores do campo, representa uma conquista na luta por direitos educativos diferentes daqueles produzidos pelo pensamento eurocêntrico.
Isto porque, "a colonialidade do saber nos revela ... um legado epistemológico do eurocentrismo que nos impede de compreender o mundo a partir do próprio mundo em que vivemos e das epistemes que lhes são próprias”. (Porto-Gonçalves, 2005, p. 3).

Com esses argumentos, pensar em processos educativos a partir do próprio mundo e das epistemes, como assinalado por Porto-Gonçalves (2005), insere o Tempo Comunidade enquanto prática educativa em giro decolonial, por razões diversas as quais abordaremos posteriormente. Por isso, a posição epistemológica assumida nesta pesquisa reitera o pensamento de Mignolo (2007, p. 29), quando defende que "el giro decolonial es la apertura y la libertad del pensamiento y de formas de vida - otras (economías-otras, teorías políticas-otras); la limpieza de la colonialidad del ser y del saber". Especialmente, ao destacar que o giro decolonial representa $\mathrm{o}$ "el desprendimiento de la retórica de la modernidad y de su imaginario imperial articulado en la retórica de la democracia ... tiene como razón de ser y objetivo la decolonialidad del poder (es decir, de la matriz colonial de poder)". (Mignolo, 2007, p. 29-30). Tal matriz constitui-se enquanto elemento estruturante da sociedade brasileira, operacionalizada, 
sobretudo, por uma lógica educativa colonial, mas que a Pedagogia da Alternância tem apresentado respostas contra-hegemônicas interessantes.

A Pedagogia da Alternância, enquanto uma dessas respostas contrahegemônicas à colonialidade do saber, demarca o campo teórico-metodológico e epistemológico da Educação do Campo, desde outras leituras e compreensões do mundo e da realidade. Principalmente, sob a ótica dos sujeitos sociais subalternizados, silenciados e ultrajados pela colonialidade/modernidade. Entre eles os atores sociais do campo que, somente na última década, conseguiram materializar, por meio das lutas sociais e políticas, processos de formação de educadores do campo para atender suas demandas históricas. Nessa ótica, inserimos-nos, estudantes e docentes da Licenciatura Interdisciplinar em Educação do Campo da UFF, para então reescrevermos a nossa história na perspectiva do Tempo Comunidade. $\mathrm{Na}$ reescrita, articulamos uma proposta de pesquisa qualitativa interpretativa que, pensada a partir do enfoque teórico-metodológico decolonial, apresenta-se como uma ferramenta crítica para desvelar a realidade social.

A realidade social a qual nos referimos está submersa nos elementos históricos, econômicos, políticos sociais e ambientais, enquanto marcas de cinco séculos de invasão, apropriação e violência na América Latina (Andrade, 2018; 2019). Logo, a abordagem interpretativa, nos ajudará a compreender essa realidade, especificamente os processos de colonização das instituições educativas e dos saberes que nelas são privilegiados. Ao tempo, nos auxiliará na análise dos dados e na construção da narrativa, pensada com os sujeitos do curso da Educação do Campo da UFF, uma vez que a abordagem interpretativa "é sempre a produção de um novo significado sobre eventos que, em seu relacionamento, não tem significados a priori. A interpretação das informações ocorre ao longo de toda a pesquisa e vai alimentando novas construções no processo". (Rossato \& Martínez, 2017, p. 344). A abordagem interpretativa envolve, nesta pesquisa, a leitura do mundo a partir do cenário próprio do pesquisador, na qual a interpretação é construída em termos de significados aos quais atribuímos valor simbólico.

As construções simbólicas interpretativas, pensadas com a Educação do Campo, com a Pedagogia da Alternância e, assim, refletida no Tempo Comunidade, traduzem as formas como “cada pesquisador constrói e reconstrói o problema de pesquisa tecido pelas suas vivências e percepções sociais, históricas, 

decolonial: a experiência do Tempo Comunidade na Universidade Federal Fluminense (UFF)...

culturais

$$
\text { e, principalmente, }
$$

epistemológicas, que é o que possibilita reconhecer a existência de um problema de pesquisa”. (Rossato \& Martínez, 2017, p. 344). Desse modo, nossas análises interpretativas, em âmbito epistemológico nessa pesquisa, foram estabelecidas, por um lado, por meio das contribuições acadêmicas provocadas com/e por interlocutores como: Aníbal Quijano, Carlos Walter Porto-Gonçalves, Catherine Walsh, Edgardo Lander, Marlene Ribeiro, Miguel Arroyo, Mônica Molina, Nelson Maldonado-Torres, Ramón Grosfoguel, Roseli Caldart e Santiago Castro-Gómez, entre outros. No que diz respeito ao problema de pesquisa, voltamo-nos, por outro lado, ao reconhecimento de uma dívida histórica em matéria de racismo epistêmico contra as populações do campo. Por essa razão, mantivemo-nos fiéis aos discursos, obtidos por meio das entrevistas, de alguns atores políticos que protagonizam a proposta de Educação do Campo na UFF.

\section{Outras formas de compreender o mundo: a experiência da Educação do Campo na UFF}

A Pedagogia da Alternância, na sua proposta de Tempo Universidade e Tempo Comunidade, se apresenta como uma aposta política decolonial, a qual possibilita diálogos entre as mais diversas epistemes existentes na América Latina. Em sua essência, promove novas prospectivas pluralistas de produção de saberes que, no Tempo Comunidade, têm como objetivo "integrar a atuação dos sujeitos educandos na construção do conhecimento necessário à sua formação". (Molina \& Freitas, 2011, p. 28). Mostra-se, dessa forma, como uma importante ferramenta de ruptura epistemológica que desestabiliza as lógicas hegemônicas de produção de conhecimento. Sinaliza, assim, oportunidades pedagógicas de libertação dos moldes coloniais de educação, sobretudo quando destaca a importância do Tempo Comunidade na minimização do abismo existente entre teoria e prática. Ademais, quando defende o princípio de liberdade humana dos povos do campo que, enquanto sujeitoshistóricos, organizam e articulam as lutas sociais emancipatórias em defesa do seu território, da sua identidade e da sua ancestralidade. Todas essas questões foram apresentadas nas entrevistas realizadas à comunidade da Licenciatura Interdisciplinar Educação do Campo da UFF, as quais podem ser visualizadas no gráfico a seguir. 


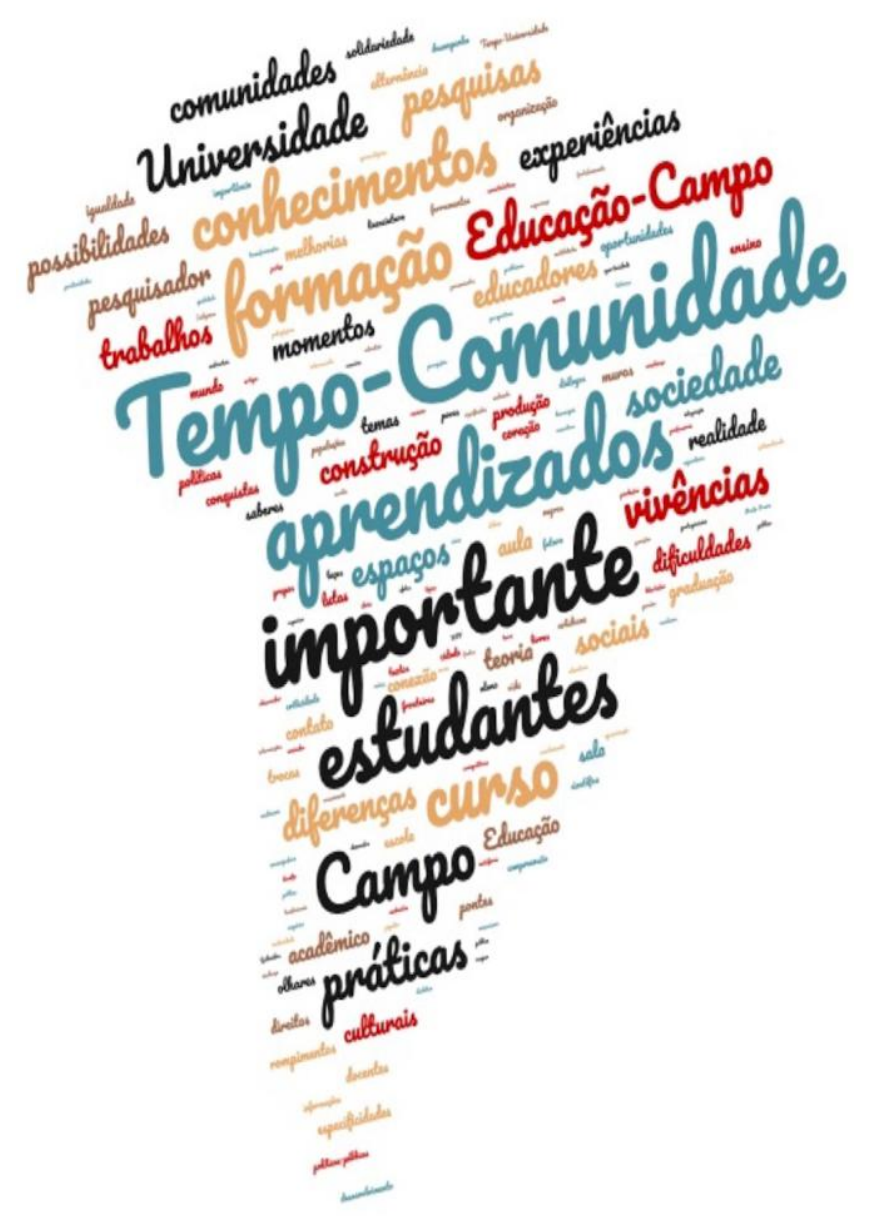

Fonte: Elaboração nossa - Dados da pesquisa (2019).

Os dados da pesquisa, expostos no gráfico 1, reiteram a importância atribuída ao Tempo Comunidade na formação de educadores do campo. A construção desse gráfico de nuvens de palavras atende a duas demandas específicas da pesquisa: $a$ ) apresentação, resumida, das falas obtidas por meio das entrevistas; $b$ ) definição das categorias de análise que foram privilegiadas, a partir das palavras que se mostraram reiterativas nos discursos dos doze estudantes e dos cinco docentes. De acordo com as informações expostas no gráfico, de um total de 553 palavras obtidas após a etapa de tratamento dos dados coletados em duas perguntas da entrevista, constituíram-se enquanto objeto de análise as seguintes palavras com as suas respectivas frequências: TempoComunidade (6,5\%); importante (4,2\%); aprendizados (3,8\%); estudantes (3,4\%); formação (2,7\%); conhecimentos (2,3\%). Com base na repetição dessas palavras, estabelecemos três categorias de análise, tal como descritas na metodologia da pesquisa. Os resultados que se inscrevem nessas categorias serão apresentados por meio de uma construção dialética que 
privilegia os discursos, obtidos por meio das entrevistas, enquanto material de primeira mão.

\section{Pontes, lutas sociais e epistêmicas: a importância do Tempo Comunidade na formação de educadores do campo}

As produções teórico-metodológicas têm destacado a relevância e as potencialidades da Pedagogia da Alternância na formação dos sujeitos do campo, em meio século de constituição e de consolidação no cenário brasileiro (Cordeiro et al., 2011). Essa relevância é reiterada nos discursos dos estudantes e dos docentes que protagonizaram essa pesquisa, cujas respostas se complementam e, ao tempo, revelam a diversidade de ideias que caracterizam a importância atribuída ao Tempo Comunidade. Essa diversidade fortalece as bases estruturais da Pedagogia da Alternância e, assim, propõem outros horizontes educativos contra-hegemônicos, os quais variam em movimentos educativos decoloniais, uma vez que "o viver precede o aprender". (Arroyo, 2014, p. 254). No curso de Educação do Campo da UFF, esses movimentos se consolidam na percepção dos sujeitos que protagonizam o Tempo Comunidade; isto é, os eixos temáticos privilegiados. Tais eixos, são formados de modo a atender às demandas dos estudantes do curso, voltadas a (re)criar e a potencializar os conhecimentos acadêmicos, a partir das realidades e das comunidades compartilhadas. Sobre essa questão, os sujeitos da pesquisa destacam que:

O Tempo Comunidade permite um envolvimento com o tema não só a partir da mediação com os livros, textos e filmes que nós evidentemente precisamos trabalhar enquanto ferramenta de entendimento de mundo, mas eles ampliam, nos recolocam no mundo. O Tempo Comunidade nos convida a protagonizar os textos, as lutas, as causas que a gente se envolve dentro de cada disciplina nas salas de aula. Rompe com a própria compreensão do significado de uma disciplina de um curso e também de universidade, entendendo que a produção de conhecimento ela se dá dentro de sala de aula, dentro dos espaços formais educativos, mas também se dá fora desses espaços $(\mathrm{P} 2)$.

As informações da pesquisa ressaltam que o Tempo Comunidade se destaca em importância social, política e epistêmica, quando recoloca o estudante em sua própria comunidade, não apenas na condição de estudante, mas, também, como educador em potencial, fruto daquela realidade. Esse argumento se fortalece no discurso de um dos entrevistados ao enfatizar que "foi no Tempo Comunidade que me reaproximei das escolas do campo, não como aluno, mas como educador, alguém disposto a mudar a realidade política e social com um viés libertador, através da educação emancipadora que o 
curso e o Tempo Comunidade proporcionam" (E9). Essa reaproximação com a comunidade a que pertence, ressignifica a percepção crítica de sua realidade, produzindo pedagogias e movimentos decoloniais que dialogam em sentido à transformação das estruturas sociais emancipatórias. Possivelmente, tais movimentos se fortalecem em função de que "a leitura crítica do mundo é um quefazer pedagógico-político indicotomizável do que-fazer político-pedagógico, isto é, da ação política que envolve a organização dos grupos e das classes populares para intervir na reinvenção da sociedade". (Freire, 2000, p. 21). Nessa reinvenção...

A Alternância, o papel dela nessa pedagogia é fazer uma conexão de conhecimentos. Conhecimentos que você tem na sua vida cotidiana com conhecimento que você aprende na universidade e, mais do que isso, a interconexão desses saberes, dos saberes práticos que você constrói cotidianamente com os saberes da universidade. Então, a Alternância tem um papel crítico de construção interativa desse conhecimento e que vai propiciar, para o aluno de Educação do campo, uma percepção muito crítica sobre o mundo que o cerca e sobre o conhecimento, uma possibilidade prática de interações do conhecimento, e isso eu acho fundamental (P4).

De acordo com os discursos apresentados, o Tempo Comunidade tem se mostrado um importante princípio teórico-metodológico que ajuda a romper com a lógica colonial, pautada no padrão da modernidade de poder/saber. A construção e fundamentação dessa lógica, historicamente, tem como base "uma específica racionalidade ou perspectiva de conhecimento que se torna mundialmente hegemônica colonizando e sobrepondo-se a todas as demais, prévias ou diferentes, e a seus respectivos saberes concretos". (Quijano, 2005, p. 115). Ao contrário disso, o Tempo Comunidade mostra-se dialética e politicamente uma proposta decolonial, caracteriza as lutas históricas de diferentes atores sociais, refletidas no tempo atual. Entre essas lutas destacamos o discurso que pontua o eixo temático que contempla discussões sobre o Ecofeminismo; ou seja “... a importância da luta das mulheres pela Terra. Estamos tentando mostrar uma vertente feminista que apoia a luta dessas mulheres e que diz que para existir uma verdadeira emancipação das mulheres, o feminismo e a agroecologia devem andar de mãos dadas" (E8). Para além dos ganhos dialéticos e políticos que se inscrevem no âmbito da formação dos educadores, a importância do Tempo Comunidade revela-se, também, para as comunidades. Tal como enfatiza o discurso do estudante, apresentado a seguir:

Estou finalizando o $5^{\circ}$ período. Faço parte do eixo Educação e Sustentabilidade. O Eixo tem amplificado a minha forma de 
entender as ferramentas da Educação do Campo e como utilizá-las. No eixo, tenho trabalhado junto com dois amigos, sobre o fechamento de escolas do campo, ... estamos estudando e aplicando no campo, conhecimentos que proporcionamos no eixo. Estamos registrando a luta da educação no Noroeste Fluminense e comparando escolas do campo que estão sendo fechadas e outras que estão tendo investimento e sendo reformadas. Estamos registrando em vídeo áudio, em forma de documentários. Nossa intenção é publicar diversos artigos e trabalhos, disponibilizando o material para fortalecer a luta (E10).

As falas dos protagonistas da pesquisa ressaltam, de diferentes formas, a importância do Tempo Comunidade na visão dos estudantes e docentes. As entrevistas sinalizam que o estreitamento de laços entre docentes-estudantescomunidades tem provocado, também, uma universidade mais humanizada, a qual reconhece a importância das trajetórias de vidas e que, portanto, busca formar educadores dispostos a pensar as escolas, os sujeitos e as aprendizagens na sua pluralidade. Nessa provocação, o Tempo Comunidade tem assumindo um papel central no curso de Educação do Campo, pois cria pontes para aproximar sujeitos e saberes historicamente separados. Sobre esta questão, a fala de um dos docentes entrevistados justifica o uso da metáfora da ponte, uma vez que o Tempo Comunidade "é realmente a ponte entre dois espaços que, infelizmente na forma como a sociedade se organizou, e se organiza ainda, são colocados como separados por muros, fronteiras, enfim, muitas vezes muros e fronteiras invisíveis" (P2).

A ideia de ponte é reiterativa nos discursos dos demais participantes da pesquisa, sobretudo quando situam que "o Tempo Comunidade acaba, de fato, promovendo uma ponte entre esses dois momentos, que muitas vezes estão apartados da formação. A formação só se concretiza quando você tem essa dialética, essa integração entre as duas partes" (P1). Os discursos indicam que o Tempo Comunidade é de grande importância na desestabilização

da colonialidade/modernidade, pautada na lógica do poder/saber, uma vez que coloca em debate o argumento de "que qualquer narrativa da modernidade que não leve em conta o impacto da experiência colonial na formação das relações propriamente modernas de poder é não apenas incompleto, mas também ideológico". (Castro-Gómez, 2005, p. 80). Na pauta da narrativa ideológica, não podemos deixar de citar os saberes esquecidos, marginalizados e perdidos, em detrimento das práticas educativas coloniais em mais de cinco séculos de invasão, apropriação e violência na América Latina. Contudo, a 
Educação do Campo vem construindo pontes para confrontar essa realidade.

\section{Tempo Comunidade e a proposta decolonial: reaprender com os territórios e com os sujeitos do campo}

O caráter pedagógico decolonial, proposto pela Pedagogia da Alternância, faz com que o processo de ensinoaprendizagem na Educação do Campo se torne mais significativo para os estudantes. A ressignificação acontece por meio do Tempo Comunidade, na real aproximação ao contexto que os estudantes estão inseridos; bem como, a partir do uso social e político dos conhecimentos adquiridos no Tempo Universidade, colocando-os em ações práticas para sua comunidade. Nesse sentido, nos propusemos a analisar, também, quais as aprendizagens que os docentes e os estudantes consideram mais significativas, construídas no Tempo Comunidade. Uma dessas aprendizagens, de acordo com os protagonistas da pesquisa, está relacionada à possibilidade de se engajar e contribuir em causas e lutas sociais das suas comunidades. Ademais, a aproximação da academia com a sociedade; isto é, o estreitamento dos laços, ou mesmo construção de pontes, na tentativa de promover uma atuação ativa voltada aos processos de liberdade, autonomia e defesa de direitos educativos diferenciados das comunidades do campo.
Essa aprendizagem, no sentido de construção da luta social, é destacada no discurso a seguir:

É muito importante trazer a realidade das nossas comunidades para dentro da universidade, e isso temos feito através do Tempo Comunidade. Os resultados são excelentes, como por exemplo, depois de dois anos de muita luta e resistência ainda permanecemos com a escola Alice do Amaral em pleno funcionamento ${ }^{[4]}$, é relevante se analisarmos que no Estado do Rio de Janeiro foram fechadas 232 escolas do campo em quase uma década, e das cinco escolas consideradas do campo pela Secretaria de Educação aqui em Pádua; três já foram fechadas em menos de dois anos. Nosso eixo foi e está sendo desenvolvido em cada período que passamos, estamos aprendendo em cada comunidade que convivemos, superando e resistindo contra os desafios existentes na Educação do Campo (E9).

As ideias de aprendizagens voltadas às demandas sociais das comunidades revelam-se como elemento representativo nas falas, principalmente dos estudantes quando destacam que "precisamos ter uma educação que fale a partir da realidade social de cada aluno, e assim, alcançar uma mudança educacional em nossa sociedade, e fazer, de fato, essa aproximação e eliminar de vez o distanciamento entre escola e sociedade" (E9). Sendo assim, os dados indicam que o Tempo Comunidade contempla uma natureza crítica, das mais distintas formas, para confrontar a colonialidade e, portanto, promover 
ferramentas pedagógicas de fortalecimento das lutas sociais contemporâneas. Em tal natureza reside muitos elementos que traduzem a reflexão-ação, uma das características marcantes da educação popular, a qual tem desempenhado um papel importante na organização das lutas dos movimentos sociais do campo, reciprocamente. Isto porque, "las luchas sociales también son escenarios pedagógicos donde los participantes ejercen sus pedagogías de aprendizaje, desaprendizaje, reaprendizaje, reflexión y acción”. (Walsh, 2013, p. 29). A reflexãoação é promovida por meio da convivência, do respeito às diferenças nas diversas formas de pensar e existir, assinalada por um dos docentes:

... o maior aprendizado é a troca, a troca e o convívio com outro, isso é fundamental. Também essa questão da solidariedade da construção de laços, essa amizade que é feita com a comunidade local onde nós estamos inseridos, acho que é o maior aprendizado. É a própria experiência do aluno no campo, no dia a dia, no fazer, no educar, no crescer juntos (P4).

A valorização das aprendizagens construídas na convivência é um aspecto extremamente potente do Tempo Comunidade, uma vez que valoriza a experiência social dos grupos construída historicamente. Os sujeitos da pesquisa entendem que "o conhecimento não é passado só em sala de aula. Temos oportunidade de conversar e dialogar com pessoas que realmente vivem no campo, pessoas que falam pela sua experiência pessoal" (E8). Outro estudante enfatizou, ainda, que "em todos os aspectos houve sempre grande aprendizado, porém, significativamente a proximidade com a comunidade" (E1). Portanto, o Tempo Comunidade se torna um espaçotempo propício para promover o giro decolonial; isto é, "un cambio de perspectiva y actitud que se encuentra en las prácticas y formas de conocimiento, ... un proyecto de transformación sistemática y global de las presuposiciones e implicaciones de modernidad, asumido por una variedad de sujetos en diálogo". (Maldonado-Torres, 2007, p. 160). Essa possibilidade de diálogos é outra aprendizagem que os protagonistas destacam, pois a Pedagogia Alternância permite conexões entre as mais diferentes epistemologias existentes, tal como destaca o docente a seguir:

Os aprendizados vinculados ao Tempo Comunidade mais significativos se estabelecem na medida que nós conseguimos fazer leitura e releitura do nosso espaço vivido. Das nossas práticas cotidianas, dentro das nossas comunidades, com auxílio do arcabouço teórico e das ferramentas teóricas que a gente adquire no Tempo Universidade. Então quando a gente consegue estabelecer esse diálogo, essa reflexão, está aí o tesouro dessa aprendizagem (P5). 
Os discursos de estudantes e docentes se retroalimentam e, por conseguinte, reiteram que o Tempo Comunidade critica quaisquer ações excludentes presentes nas relações verticalizadas impostas pela colonialidade/modernidade do saber. Isto porque, a modernidade, vista desde o pensamento decolonial, "é uma máquina geradora de alteridades que, em nome da razão e do humanismo, exclui de seu imaginário a hibridez, a multiplicidade, a ambiguidade e a contingência das formas de vida concretas". (Castro-Gómez, 2005, p. 80). Dessa forma, o Tempo Comunidade além de promover aprendizagens significativas, também propõe uma transgressão ao modelo hegemônico de educação, para então criar uma nova pedagogia. Enquanto formas de vida concretas, o Tempo Comunidade coloca em pauta "os saberes tradicionais, os saberes que os alunos já trazem consigo a partir das suas vivências nas suas comunidades, práticas que vão estabelecendo dentro da vida ... relacionadas ao seu modo de vida, seu trabalho e sua forma de trabalhar" (P5). Enquanto transgressão, destacamos o seguinte discurso: "a aprendizagem de que mais me chamou atenção no meu eixo foi ver um pouco mais da organização educacional do MST aqui no estado do Rio de Janeiro" (E11).

Formas de vidas concretas e transgressão formam uma nova perspectiva pedagógica decolonial, uma vez que o Tempo Comunidade na UFF contempla sujeitos-históricos, epistemologias e territorialidades que foram subalternizados pelo processo de colonização. Mas que, historicamente, reinventam as lutas contrahegemônicas, quando compartilham, comunidades-estudantes-docentes, as experiências de resistência histórica aos elementos que caracterizam a colonização. Reinventam, assim, outras aprendizagens que somente são possíveis por meio da construção da experiência, nas quais "o Tempo Comunidade é de minha sensibilidade enquanto um tempo de entender e experienciar o campo em suas diversas categorias de análise referenciadas em salas de aulas, e mesmo as não referenciadas" (E12). Para além disso, permite "aos alunos do curso se deleitem com as infinitas experiências de análise que o Campo tem a nos oferecer, onde talvez nunca tivemos ou teríamos tal possibilidade" (E12). Com esses discursos, entendemos que o Tempo Comunidade potencializa aprendizagens únicas, as quais não podemos adjetivá-las, pois cada uma representa modos de vidas e de leituras de mundo singulares. 


\section{A experiência do Tempo Comunidade: habilidades e conhecimentos potencializados}

Ao analisarmos os dados expostos no gráfico 1, relacionando-os à terceira categoria de análise estabelecida conhecimentos que, na visão dos protagonistas da pesquisa, foram potencializados com o Tempo Comunidade-, é possível observar nas respostas de estudantes e docentes alguns pontos que se destacaram. Um desses refere-se às pesquisas que são construídas durante o Tempo Comunidade, as quais potencializam, não somente o olhar de pesquisador dos estudantes, mas os coloca diante da realidade, em um processo de reflexão-ação. Nos discursos de docentes e estudantes, essa característica do Tempo Comunidade constitui-se como algo fundamental, pois em função da inserção dos estudantes na pesquisa, desde o primeiro período do curso, "os alunos da Educação do Campo acabam tendo uma maior facilidade, digamos assim, de transitarem nessas possibilidades da academia" (P1). Em seu discurso, a docente P1 complementa, ainda, que o “Tempo Comunidade dá essa segurança para o momento de pesquisa, de um olhar de pesquisador, de observador em campo, trabalhos de campo, mesmo que alguns grupos não sejam trabalho de campo".
Nesse processo de pesquisa, os docentes também aprendem, a fala a seguir traduz essas aprendizagens:

... o maior aprendizado é o aprendizado de pesquisa, mas na prática da pesquisa. Os alunos na construção do nosso Tempo Comunidade, como ele é na UFF, pronuncia isso, a construção do aluno, ele como aluno pesquisador. No caso específico do meu tempo comunidade, o que mais foi apreendido, acredito eu, foi a questão de si, do seu papel no mundo acadêmico. Esses alunos ao se perceberem como negros, uma pessoa que tem uma série de percalços e barreiras de entrada na universidade, entendem o quanto a sociedade brasileira é estruturalmente racista. Esses são um dos aprendizados que eu acho importante, os alunos percebem o quanto existe um funil para entrada no ensino superior. Quanto maior o nível do ensino, mais difícil é a entrada para o estudante negro, e eu acho que isso é o grande aprendizado na prática $(\mathrm{P} 3)$.

A importância atribuída às potencialidades da formação, pensada com a pesquisa, revela-se, também, no discurso de outro docente que enfatiza que "embora sejamos uma licenciatura, também desde o primeiro período todos e todas já se colocam na condição de pesquisadoras e pesquisadores" (P2). Para além das habilidades conquistadas por meio da pesquisa, destacamos os conhecimentos potencializados que, para os protagonistas da pesquisa, relacionam-se aos saberes dos povos do campo. Tais saberes, devido às 
lógicas coloniais opressoras, ocuparam um lugar de inferioridade epistemológica, imposto desde o início da invasão europeia na América Latina. Nesse sentido, como elucida Lander (2005, p. 10), “com o início do colonialismo na América inicia-se não apenas a organização colonial do mundo mas -simultaneamente- a constituição colonial dos saberes, das linguagens, da memória”. Ao levar isso em consideração, o Tempo Comunidade, ao assumir uma posição pedagógica decolonial, desarticula essa colonialidade do saber, trazendo para o espaço acadêmico os saberes das populações tradicionais e camponesas, tal como sinaliza o discurso a seguir:

O Tempo Comunidade não só oficializa o processo de produção e realização dos saberes do Povo, dos saberes tradicionais, mas ele valoriza esses saberes dentro de uma proposta dialógica, entre saber científico e saber tradicional. E, também, ajuda a tensionar dentro da academia essa perspectiva de conhecimento universal que universaliza as propostas e as perspectivas coloniais europeias e subjugam, desacreditam, diminuem os saberes dos povos originários, então o Tempo Comunidade é mais que essencial (P5).

O papel emancipador das colonialidades assumido pelo Tempo Comunidade revela-se constantemente nos dados da pesquisa, sobretudo quando os estudantes enfatizam que "sua política pedagógica é diferenciada e libertadora.
Contradiz a lógica de ensino convencional e podemos dizer que também a conjuntura na sociedade contemporânea" (E1). Igualmente, reconhecem que "o curso ocupa a linha de frente em uma batalha contra as diversas formas de opressão, tal posicionamento nos desperta um senso crítico e intolerante frente às ações de exclusão, discriminação e intolerância (E7)". As ações citadas podem ser diversas, mas se encontram em um ponto de convergência; isto é, na colonialidade do saber, potencializada por meio do racismo epistêmico. Tal racismo é uma das categorias de racismo menos discutida no sistema capitalista e eurocêntrico, uma vez que considera os conhecimentos produzidos fora do mundo ocidental, como inferiores aos conhecimentos eurocêntricos (Grosfoguel, 2007). Para desestabilizar essa colonialidade, "o Tempo Comunidade proporcionou esse encontro, de saberes e histórias que muitas vezes, não chegam à universidade" (E9).

Os discursos de estudantes e docentes, com os quais construímos essa pesquisa, colocam no centro do diálogo as habilidades e os conhecimentos que são potencializados no Tempo Comunidade. Conhecimentos que superam os objetivos propostos nas ementas das disciplinas, mas que se refletem enquanto diálogos interepistêmicos com diferentes sujeitos e 
territórios, os quais contribuem para o enriquecimento da formação dos educandos do campo. Na pauta de tais diálogos, os conhecimentos que são potencializados apresentam-se diversos, inclusive "a relação das ervas medicinais com os modos de vida e a forma como perpassa gerações" (E3). Isso é possível mediante o caráter interdisciplinar do curso de Educação do Campo da UFF, uma vez que os eixos temáticos do Tempo Comunidade dialogam e se complementam. Esses diálogos, de acordo com os objetivos dos eixos temáticos, acontecem na perspectiva de potencializar os conhecimentos que se inscrevem, principalmente, nas seguintes interseccionalidades: ambiente; gênero; raça; saúde; território; movimentos sociais.

Todos os conhecimentos potencializados no Tempo Comunidade, a partir dessas interseccionalidades, revelamse na formação dos estudantes de Educação do Campo da UFF. Ademais, o Tempo Comunidade permite aos estudantes acesso antecipado ao futuro profissional, pois, "muitas vezes, estamos conhecendo nosso campo de trabalho, que são as escolas e os povos dos campos" (E10). Esses aspectos revelam algumas das potencialidades do Tempo Comunidade, as quais, conforme sugerido por um dos docentes, poderiam ser aproveitadas para fortalecer a experiência da formação em outros cursos de graduação. Por isso, a percepção desse docente -P4- "é a mais promissora possível. Eu vejo coisas grandes para esse curso, tem grande potencial que é importante sim para nossa sociedade e para o educador". Complementa, ainda, "acho que esse modelo, que é o modelo essencialmente inovador, poderia ser aplicado em outros cursos também, porque levar essa vivência seria muito importante" (P4). Todas essas potencialidades apenas têm significado em função das lutas históricas dos movimentos sociais que, ainda em construção, desafiam as lógicas coloniais do tempo presente, seja nas universidades, seja nas formas de pensar e projetar a educação.

\section{Algumas considerações tecidas com o Tempo Comunidade...}

Com esta pesquisa foi possível destacar que, entre outros aspectos, a construção da Pedagogia da Alternância na Licenciatura Interdisciplinar em Educação do Campo da UFF acontece em espaços/tempos emancipatórios das colonialidades impostas à América Latina. O Tempo Comunidade, nesse curso, potencializa conhecimentos, aprendizagens e habilidades pensadas em espaços sociais historicamente marginalizados pela lógica da modernidade saber/poder, tais como: 
assentamentos, quilombos, sindicatos de trabalhadores rurais, movimentos sociais, escolas do campo e a própria vida no campo. Revela-se, desse modo, como um laboratório de experiências sociais, políticas e ambientais que desafiam e desestabilizam, de diferentes formas, o projeto de colonialidade/modernidade que impera em território nacional. Apesar dessa e de outras conquistas significativas do curso, as tensões políticas atuais ampliam, novamente, a ideologia da negação do direito à educação diferenciada para as populações do campo. Isso porque, algumas ações políticas do governo federal atual têm promovido medidas de contingenciamento de investimentos destinados à educação pública, as quais comprometem, diretamente, a existência e a permanência dos cursos de Educação do Campo nas universidades federais.

Em âmbito local, os resultados da pesquisa indicam que estudantes e docentes da Educação do Campo da UFF enfrentam dificuldades, diariamente, para desenvolverem o projeto ideológico da Educação do Campo, de forma a atender as especificidades da comunidade acadêmica do curso. Uma dessas dificuldades está relacionada à fragilidade da infraestrutura física da UFF, Campus de Santo Antônio de Pádua, para promover o acesso e a permanência das populações do campo na universidade. A ausência dessa infraestrutura, principalmente alojamentos e restaurante universitário, resulta na desistência e no distanciamento de estudantes procedentes de aldeias indígenas, quilombos e outros centros rurais. Para além disso, a monocultura do saber apresenta-se como outra dificuldade encontrada pela comunidade acadêmica do curso, uma vez que na universidade predominam, ainda, as lógicas coloniais de produção do saber, as quais pouco dialogam com a concepção de produção da experiência, pautada em outras epistemologias que não sejam as ocidentais. Logo, a concepção de monocultura do saber contribui para que a própria universidade tenha dificuldades em compreender, em sua integralidade, a Pedagogia da Alternância e, por conseguinte, o Tempo Comunidade. Em outras palavras, a importância do Tempo Comunidade para a Educação do Campo enquanto proposta emancipatória decolonial, desestabilizadora da opressão e da subalternização epistemológica colonial.

Mesmo com as dificuldades encontradas pela comunidade acadêmica do curso de Educação do Campo da UFF, os resultados da pesquisa sinalizam, também, a importância do Tempo Comunidade como espaço de construção e 
fortalecimento de autonomias, de participações e de colaborações em diferentes frentes sociais. Entre elas, a articulação em movimentos sociais que desencadearam no impedimento do fechamento de escolas do campo na região. Todas essas questões revelam, portanto, a potencialidade do Tempo Comunidade para a projeção e compromisso com as responsabilidades compartilhadas, em defesa de direitos educativos diferenciados. Especialmente, quando a união entre estudantes e docentes da UFF, moradores da comunidade local e funcionários da Escola Municipal Alice do Amaral Peixoto, localizada na zona rural da cidade de Santo Antônio de Pádua- RJ, impediram que a referida escola fosse fechada pelo poder Público Municipal. Todos esses aspectos podem ser considerados como elementos pedagógicos decoloniais identificados na construção do curso.

Para além disso, os resultados destacam o Tempo Comunidade como provocador de tensões políticas emancipatórias, uma vez que a aproximação, os laços de afetividade, a amizade e a experiência social construída com as comunidades, contagiam outros atores sociais a se insurgirem contra as práticas de violências e negação de direitos. Ressaltam, também, a contribuição do Tempo Comunidade nos processos de transformação da realidade, na qual o poder da ação-reflexão das práticas sociais nos territórios -geográficos e epistemológicos- da Educação do Campo desencadeiam ações de fortalecimento da cidadania e de organização das lutas sociais. Ao considerarmos todos esses elementos que permeiam a prática educativa da Pedagogia da Alternância, inscritos e vivenciados no Tempo Comunidade, reverenciamos as lutas sociais dos movimentos da Educação Campo por terem construído uma proposta educativa inclusiva de saberes, de sujeitos e territorialidades. Nessa inclusão, o significado simbólico do Tempo Comunidade, pensado a partir da construção da experiência nesta pesquisa, revela o seu caráter principal: a luta da Educação do Campo em giro decolonial.

\section{Referências}

Andrade, F. M. R. (2018). Educação Ambiental em miradas integrativas e restaurativas: currículos educativos na Amazônia. Revista Espaço do Currículo (Online), 11(3), 297-310. Doi: https://doi.org/10.22478/ufpb.1983$\underline{1579.2018 \mathrm{v} 3 \mathrm{n} 11.41937}$

Andrade, F. M. R. (2019). Natureza e representações que r-existem: cinco séculos de invasão, apropriação e violência na Amazônia brasileira. REMEA - Revista Eletrônica do Mestrado em Educação Ambiental, 36(2), 207-227. Doi: https://doi.org/10.14295/remea.v36i2.9039 
Andrade, F. M. R., Nogueira, L. P. M., \& Rodrigues, M. P. M. (2019). Tempo Comunidade - espaçotempo potencializador de experiências na formação de educadores do campo. In Costa, A. D. (Org.). Cultura, cidadania e políticas públicas 2 (pp 154-163). Ponta Grossa (PR): Atena Editora. Doi: https://doi.org/10.22533/at.ed.7801925011 $\underline{5}$

Arroyo, M. G. (2012). Formação de Educadores do Campo. In Caldart, R. et al. (Orgs.). Dicionário da Educação do Campo (pp 361-367). Rio de Janeiro, São Paulo: Escola Politécnica de Saúde Joaquim Venâncio, Expressão Popular.

Arroyo, M. G. (2014). Outros sujeitos, outras pedagogias. Editora Vozes Limitada.

Ballestrin, L. (2013). América Latina e o giro decolonial. Revista Brasileira de Ciência Política, (11), 89-117.

Castro-Gómez, S. (2005). Ciências Sociais, violência epistêmica e o problema da "invenção do outro". In Lander, E. (Org.). Colonialidade do poder, eurocentrismo e América Latina. A colonialidade do saber: eurocentrismo e ciências sociais. Perspectivas Latino-Americana (pp. 80106). Colección Sur Sur. CLACSO, Ciudad Autónoma de Buenos Aires.

Brasil. (1996). Lei n. 9.394, de 20 de dezembro de 1996. (1996, 23 de dezembro). Estabelece as Diretrizes e Bases da Educação Nacional. Recuperado de: http://www.senado.gov.br/sf/legislacao

Brasil. (2010). Decreto $\mathrm{n}^{\mathrm{o}}$. 7.352/2010. (2010, 4 de Novembro). Dispõe sobre a política de educação do campo e o Programa Nacional de Educação na Reforma Agrária - PRONERA. Recuperado de: http://www.planalto.gov.br/ccivil_03/_ato2 007-2010/2010/decreto/d7352.htm
Caldart, R. S. (2002). Por Uma Educação do Campo: traços de uma identidade em construção. In Kolling, E. J. et al. (Orgs.). Educação do Campo: identidade $e$ políticas públicas (pp. 18-25). Brasília, DF: articulação nacional Por Uma Educação do Campo, 2002. Coleção Por Uma Educação do Campo, n. 4.

Caldart, R. S. (2008). Sobre a Educação do Campo. In Santos, C. (Org.). Educação do Campo: Campo-políticas públicaseducação (pp. 67-86). Brasília: Incra; MDA.

Cordeiro, G. N. K., Reis, N. S., \& Hage, S. M. (2011). Pedagogia da Alternância e seus desafios para assegurar a formação humana dos sujeitos e a sustentabilidade do campo. Em Aberto, Brasília, 24(85), 115-125.

Doi:

http://dx.doi.org/10.24109/2176-

6673.emaberto.24i85.2489

Ferreira, M., \& Molina, M. C. (2016). Ensino Superior e Alternância de tempos educativos - entrelaçando perspectivas para a formação de educadores do campo. In Anais do XXIV Seminário Nacional UNIVERSITAS/BR (pp. 1705-1722) Recuperado de: http://www.ppe.uem.br/xxivuniversitas/ana is/trabalhos/e 7/7-011.pdf

Freire, P. (2000). Pedagogia da Indignação: cartas pedagógicas e outros escritos. São Paulo: UNESP.

Grosfoguel, R. (2007). Dilemas dos estudos étnicos norte-americanos: multiculturalismo identitário, colonização disciplinar e epistemologias descoloniais. Ciência e Cultura, 59(2), 32-35.

Lander, E. (2005). Ciências sociais: saberes coloniais e eurocêntricos. In Lander, E. (Org.). Colonialidade do poder, eurocentrismo e América Latina. A colonialidade do saber: eurocentrismo $e$ 
ciências sociais. Perspectivas LatinoAmericana (pp. 8-23). Colección Sur Sur. CLACSO, Ciudad Autónoma de Buenos Aires.

Maldonado-Torres, N. (2007). Sobre la colonialidad del ser: contribuciones al desarrollo de un concepto. In CastroGómez, S., \& Grosfoguel, R. (Orgs.). El Giro Decolonial: reflexiones para una diversidad epistémica más allá del capitalismo global (pp. 127-167). Bogotá: Siglo del Hombre Editores; Universidad Central, Instituto de Estudios Sociales Contemporáneos, Pontificia Universidad Javeriana, Instituto Pensar, 2007.

Mignolo, W. (2007). El Pensamiento Decolonial: Desprendimiento y Apertura. Un manifesto. In Castro-Gómez, S., \& Grosfoguel, R. (Orgs.). El Giro Decolonial: reflexiones para una diversidad epistémica más allá del capitalismo global (pp. 25-46). Bogotá: Siglo del Hombre Editores; Universidad Central, Instituto de Estudios Sociales Contemporáneos, Pontificia Universidad Javeriana, Instituto Pensar.

Molina, M. C. (2015). Expansão das licenciaturas em Educação do Campo: desafios e potencialidades. Educar em Revista, 55, 145-166. Doi: http://dx.doi.org/10.1590/0104-4060.39849

Molina, M. C., \& Freitas, H. C. A. (2011). Avanços e desafios na construção da Educação do Campo. Em Aberto, 24(85), 17-31.

Porto-Gonçalves (2005). Apresentação da edição em português. In Lander, E. (Org.). Colonialidade do poder, eurocentrismo e América Latina. A colonialidade do saber: eurocentrismo e ciências sociais. Perspectivas Latino-Americana (pp. 3-5). Colección Sur Sur. CLACSO, Ciudad Autónoma de Buenos Aires.
Quijano, A. (2005). Colonialidade do poder, eurocentrismo e América Latina. In Lander, E. (Org.). Colonialidade do poder, eurocentrismo e América Latina. A colonialidade do saber: eurocentrismo $e$ ciências sociais. Perspectivas LatinoAmericana (pp. 107-130). Colección Sur Sur. CLACSO, Ciudad Autónoma de Buenos Aires.

Ribeiro, M. (2010). Movimento camponês trabalho e educação: liberdade, autonomia, emancipação: princípios/fins da formação humana. São Paulo, SP: Expressão Popular.

Rossato, M., \& Martínez, A. M. (2017). A metodologia construtiva-interpretativa como expressão da Epistemologia Qualitativa na pesquisa sobre o desenvolvimento da subjetividade. Investigação Qualitativa em Educação, (1), 343-352.

Santos, C. A. (2012). Programa Nacional de Educação na Reforma Agrária (PRONERA). In Caldart, R. et al. (Orgs.). Dicionário da Educação do Campo (pp. 631-639). Rio de Janeiro, São Paulo: Escola Politécnica de Saúde Joaquim Venâncio, Expressão Popular.

Walsh, C. E. (Ed.). (2013). Pedagogías decoloniales: prácticas insurgentes de resistir, (re) existir y (re) vivir. Abya Yala.

[1] Texto produzido a partir de uma pesquisa realizada em âmbito do Tempo Comunidade 2019.1 .

[2] Em função de uma posição teórica integrativa, assumida com a pesquisa, optamos por não traduzir as citações das obras escritas na língua castelhana.

[3] Dados da Secretaria Acadêmica - Sistema IDUFF (2019).

[4] Melhores informações sobre a articulação comunitária contra o fechamento de Escolas do Campo podem ser consultadas em: Neves, L. C. et al. (2019). Memória social e resistência: organização comunitária contra o fechamento da 
Escola Alice do Amaral Peixoto. In Costa, A. D. (Org.). Cultura, cidadania e políticas públicas 4 (pp. 130-137). Ponta Grossa (PR): Atena Editora.

\section{Informações do artigo / Article Information}

Recebido em : 14/07/2019

Aprovado em: 30/09/2019

Publicado em: 19/12/2019

Received on July 14th, 2019

Accepted on September 30th, 2019

Published on December, 19th, 2019

Contribuições no artigo: A autora Francisca Marli Rodrigues de Andrade liderou a elaboração e gestão do projeto de pesquisa, assim como na sua supervisão, conceitualização, metodologia, validação dos instrumentos de coletas de dados, análises dos dados, software, redação da versão publicada. Os autores Letícia Pereira Mendes Nogueira, Marcela Pereira Mendes e Lucas do Couto Neves ajudaram como colaboradores na elaboração do projeto de pesquisa, na conceitualização, metodologia, coletas de dados e análises, e na redação da versão final publicada.

Author Contributions: The author Francisca Marli Rodrigues de Andrade led the elaboration and management of the research project, as well as its supervision, conceptualization, methodology, validation of data collection instruments, data analysis, software, writing of the published version. The authors Letícia Pereira Mendes Nogueira, Marcela Pereira Mendes and Lucas do Couto Neves helped as collaborators in the elaboration of the research project, in the conceptualization, methodology, data collection and analysis, and in the writing of the final published version.

Conflitos de interesse: Os autores declararam não haver nenhum conflito de interesse referente a este artigo.

Conflict of Interest: None reported.

\section{Orcid}

Francisca Marli Rodrigues de Andrade

(iD) http://orcid.org/0000-0001-6450-5911

Letícia Pereira Mendes Nogueira

(iD) http://orcid.org/0000-0002-1393-8327

Lucas do Couto Neves

(iD) http://orcid.org/0000-0003-1071-8545

Marcela Pereira Mendes Rodrigues

(iD) http://orcid.org/0000-0003-3104-9555

Como citar este artigo / How to cite this article

APA

Andrade, F. M. R., Nogueira, L. P. M., Neves, L. C., \&
Rodrigues, M. P. M. (2019). Educação do Campo em giro decolonial: a experiência do Tempo Comunidade na Universidade Federal Fluminense (UFF). Rev. Bras. Educ. Camp., $4, \quad$ e7178. DOI: http://dx.doi.org/10.20873/uft.rbec.e7178

ABNT

ANDRADE, F. M. R.; NOGUEIRA, L. P. M.; NEVES, L. C.; RODRIGUES, M. P. M. Educação do Campo em giro decolonial: a experiência do Tempo Comunidade na Universidade Federal Fluminense (UFF). Rev. Bras. Educ. Camp., Tocantinópolis, v. 4, e7178, 2019. DOI: http://dx.doi.org/10.20873/uft.rbec.e7178 